\title{
Sobre las causas de la extrema violencia en Chile: una réplica
}

\author{
On the causes of extreme violence in Chile: a rejoinder
}

Señor Editor,

Desearía comentar brevemente la carta "Reflexiones en torno a la extrema violencia que ha acompañado a la crisis social de Chile" del Dr. Otto Dörr (Dörr, 2019). Sin lugar a dudas una revista médica es el lugar adecuado para comentar y discutir el fenómeno de la violencia en el país, sus probables causas, su prevención y sus potenciales repercusiones futuras. Esta discusión además de condenar justificadamente el fenómeno de la violencia debiera analizar imparcialmente, exhaustivamente y científicamente, si es posible, sus potenciales causas.

Soy de la opinión que en su carta el Dr. Dörr se aleja de la imparcialidad necesaria para este análisis al concentrar sus comentarios sobre la violencia, solamente en aquella violencia que proviene de la protesta juvenil e ignora la violencia de las fuerzas policiales y del ejercito que de acuerdo a las organizaciones nacionales e internacionales de derechos humanos como Naciones Unidas (Naciones Unidas, 2019), Comisión Interamericana de Derechos Humanos de la Organización de Estados Americanos (Nash - Rojas, 2019), Amnistía Internacional (Amnesty International, 2019) y Human Rights Watch (Human Rights Watch, 2020) han cometido violentas y numerosas vulneraciones de estos derechos de una manera inaceptable. Por ejemplo, de acuerdo al Instituto Nacional de Derechos Humanos en los últimos meses se ha determinado que 3838 personas han sido heridas (un número importante, 1933, por proyectiles de armas de fuego), siendo un número significativo de ellas mujeres (462) y niños (288) (Instituto Nacional de Derechos Humanos Chile, 19 de marzo, 2020). Cuatrocientas ochenta personas han resultado con lesiones oculares serias por el accionas de las fuerzas policiales y existen 620 denuncias por tortura y 257 por violencia sexual, principalmente contra mujeres (Instituto Nacional de Derechos Humanos Chile, 2020). El Instituto Nacional de Derechos Humanos ha presentado 1805 querellas por violaciones de los derechos humanos de adultos y niños, incluyendo 1083 por torturas y 265 por desnudamientos y tocaciones (Instituto Nacional de Derechos Humanos Chile, 2020) y según el diario inglés The Guardian (Boddenberg \& McGowan, 2020) más de 180 menores de edad han sido mantenidos en prisión por semanas y meses sin imputaciones claras de delitos.

Al no considerar en su análisis los hechos de violencia gubernamental arriba consignados, el autor de dicha carta elimina arbitrariamente como causa posible e importante de la violencia juvenil, que esta sea una posible y natural reacción a la violencia estatal y con ello limita el análisis holístico del problema. El texto excluye caprichosamente también la existencia de reclamos juveniles que pudieran justificar en parte la violencia como son el alto costo y la mala calidad de la educación en Chile, el desempleo juvenil y los bajos salarios de la gente joven, situaciones modificables con la implementación de adecuadas políticas económica y sociales (Kremerman et al., 2016; Duran \& Kremerman, 2017; Galvez \& Kremernan, 2019). El Dr. Dörr pareciera dar la razón a los reclamos juveniles cuando reconoce que en Chile se necesita de una profunda reforma de la educación como es solicitada por la gran mayoría de los individuos que protestan y la cual es necesaria para mejorar el lenguaje y las interacciones sociales. El texto habla de una crisis moral, sin embargo, se abstrae de nombrar como parte determinante de esta crisis ética a la corrupción generalizada y documentada que afecta a las tres ramas del gobierno, a las iglesias, a las fuerzas armadas y a carabineros y a una serie de actividades productivas y económicas en el país. Sin lugar a dudas la corrupción generalizada de distintas autoridades puede ser unos de los factores que ayudan a menoscabar su idoneidad y el principio de autoridad como lo señala el texto. En su análisis de las causas de la violencia el texto descarta también, equivocadamente y parcialmente a mi juicio a los factores económicos y sociales como causa de esta violencia, ignorando las estadísticas de organismos nacionales e internacionales que indican que una proporción importante de la población chilena,

(1) División de Obstetricia y Ginecología, Escuela de Medicina, Pontificia Universidad Católica de Chile. Autor de correspondencia:jpoblete@med.puc.cl 
especialmente jóvenes y ancianos, carecen universalmente de salarios y pensiones adecuadas, acceso a la educación y a la vivienda y a un cuidado de salud preventivo y curativo eficiente y humano (Kremerman et al., 2016; Duran \& Kremerman, 2017; Cuadrado, 2018; Galvez \& Kremernan, 2019).

Para finalizar creo que las limitaciones señaladas de la carta del Dr. Dörr al Editor, coartan su capacidad para ayudar a entender el fenómeno de la violencia política en Chile y tienden de una manera improcedente a culpar de esta violencia a supuestos componentes biológicos y psicológicos de la personalidad de las víctimas de ella. Esta aproximación, que encuentra las causas de la violencia en elaboradas construcciones abstractas y en imaginarios factores biosociológicos de los individuos blancos de ella, fue totalmente desautorizada en base a principios científicos y éticos en los EE.UU., (Lewontin, 1982; Wright, 1995) cuando se la intentaba usar para explicar la putativa extrema violencia de la población Afro -Americana en los años 1960 -70 y en Sud África cuando se la usaba para tratar de explicar la rebelión a menudo violenta contra el régimen político y económico de Apartheid. En resumen, los juicios parciales y carentes de fundamentos sólidos del Dr. Dörr confunden más que ayudan a entender el fenómeno de la violencia social en Chile y sus causas. Pero también, en lo que creo es más serio, culpan a las víctimas de la violencia estatal de ser las causantes de ella, cerrando el diagnóstico de las causas de la violencia con una perversa tautología.

Me despido cordialmente.

\section{Felipe Cabello}

Departamento de Microbiología e Inmunología. New York Medical College Valhalla, EE.UU.

cabello@nymc.edu

\section{Referencias}

Amnesty International (2019). Chile: Amnesty International denounces human rights violations to the Inter-American Commission on Human Rights. 11 November, 2019. Accedida en https://www.amnesty.org/en/latest/news/2019/11/chile-amnistia-internacional-denunciara-violaciones-ante-cidh/ el 24 de marzo de 2020.

Boddenberg S. \& McGowan C. (2020). 'Our children are going to prison': Chile holds scores of minors arrested during protests. The Guardian, March 2. Accedida en https://www.theguardian.com/ world/2020/mar/02/chile-protests-minors-held-prison el 24 de marzo de 2020.
Cuadrado C. (2018). Perspectivas de la salud en Chile y sus reformas. Cuadernos medico sociales. No 1.25 de Abril. Colegio Médico de Chile. Santiago. Chile. Accedida en http://cms.colegiomedico.cl/perspectivas-de-la-salud-en-chile-y-sus-reformas/, el 24 de marzo de 2020

Dörr O. (2019). Reflexiones en torno a la extrema violencia que ha acompañado a la crisis social de Chile. ARS Medica, Revista de Ciencias Médicas 44. 5-7.

Duran G \& Kremerman M. (2017). Debate de pobreza en Chile. Documentos de trabajo del área de salarios u desigualdad. Ideas para el buen vivir. No 11. Fundación Sol. Santiago. Chile. Accedida en http://www.fundacionsol.cl/wp-content/uploads/2017/07/ Pobreza-Julio-2017-1.pdf el 24 de marzo de 2020

Galvez R \& Kremerman M. (2019). Pensiones bajo el mínimo. Ideas para el buen vivir..No. 16. Fundación Sol. Santiago. Chile. Accedida en http://www.fundacionsol.cl/wp-content/uploads/2019/07/ Pensiones-bajo-el-minimo-2019-1.pdf el 24 de marzo de 2020.

Human Rights Watch (2019). Chile: Police Reforms Needed in the Wake of Protests Excessive Force Against Demonstrators, Bystanders; Serious Abuse in Detention. November 26. Accedida en https://www.hrw.org/news/2019/11/26/chile-police-reforms-needed-wake-protests\#, el 24 de marzo de 2020.

Instituto Nacional de Derechos Humanos Chile, 19 de marzo (2020). Reporte de Estadísticas. Accedida en https://www.indh.cl/ el 24 de marzo de 2020.

Instituto Nacional de Derechos Humanos Chile, 18 de febrero. Reporte de Estadisticas. Accedida en https://www.indh.cl/ el 24 de marzo de 2020.

Kremerman M, Páez A y Sáez B. (2016). Endeudar para gobernary mercantilizar: El caso del CAE. Estudios de la Fundación Sol. Santiago, Chile. Accedida en http://www.fundacionsol.cl/wp-content/ uploads/2016/04/Estudio-CAE-2016.pdf el 24 de marzo de 2020.

Lewontin RC..(1982). Biological determinism. The Tanner Lectures on Human Values. The University of Utah. Marzo 31 y Abril 1. Salt Lake City. Utah..EE.UU. Accedida en https://tannerlectures.utah. edu/_documents/a-to-z/l/lewontin83.pdf. el 24 de marzo de 2020. Naciones Unidas (2019). Informe de la Oficina de Derechos Humanos de la ONU sobre la crisis en Chile describe múltiples violaciones de derechos humanos de Carabineros y hace un llamado a reformas. Accedida en https://www.ohchr.org/SP/NewsEvents/Pages/DisplayNews.aspx?NewsID=25423\&LangID=S. el 24 de marzo de 2020. 
Cabello

Nash-Rojas C. (2019). Informe CIDH condena las violaciones gra-

Wright R, (1995). The biology of violence. The New Yorker, March ves, masivas y repetitivas de derechos humanos en Chile. CIPER. 6. New York. EE.UU.

Accedida en https://ciperchile.cl/2019/12/10/informe-cidh-condena-las-violaciones-graves-masivas-y-repetitivas-de-derechos-humanos-en-chile/. el 24 de marzo de 2020. 